\title{
Leukotriene receptor antagonists in monotherapy or in combination with antihistamines in the treatment of chronic urticaria: a systematic review
}

\author{
Gabriele Di Lorenzo' \\ Alberto D'Alcamo' \\ Manfredi Rizzo' \\ Maria Stefania Leto-Barone' \\ Claudia Lo Bianco' \\ Vito Ditta' \\ Donatella Politi' \\ Francesco Castello' \\ Ilenia Pepe' \\ Gaetana Di Fede ${ }^{2}$ \\ GiovamBattista Rini' \\ 'Dipartimento di Medicina clinica \\ e delle Patologie Emergenti; \\ 2Dipartimento di Discipline \\ Chirurgiche ed Oncologiche, \\ Università degli Studi di Palermo, Italy
}

Correspondence: Gabriele Di Lorenzo Dipartimento di Medicina Clinica e delle Patologie Emergenti, Via del Vespro,

$|4|$ - $90 \mid 27$ Palermo, Italy

$\mathrm{Tel}+390916552973$

Fax +3909I 6555995

Email dilo60I@unipa.it

\begin{abstract}
In vitro and in vivo clinical and experimental data have suggested that leukotrienes play a key role in inflammatory reactions of the skin. Antileukotriene drugs, ie, leukotriene receptor antagonists and synthesis inhibitors, are a class of anti-inflammatory drugs that have shown clinical efficacy in the management of asthma and in rhinitis with asthma. We searched MEDLINE database and carried out a manual search on journals specializing in allergy and dermatology for the use of antileukotriene drugs in urticaria. Montelukast might be effective in chronic urticaria associated with aspirin (ASA) or food additive hypersensitivity or with autoreactivity to intradermal serum injection (ASST) when taken with an antihistamine but not in mild or moderate chronic idiopathic urticaria [urticaria without any possible secondary causes (ie, food additive or ASA and other NSAID hypersensitivity, or ASST)]. Evidence for the effectiveness of zafirlukast and the 5-lipoxygenase inhibitor, zileuton, in chronic urticaria is mainly anecdotal. In addition, there is anecdotal evidence of effectiveness of antileukotrienes in primary cold urticaria, delayed pressure urticaria and dermographism. No evidence exists for other physical urticarias, including cholinergic, solar and aquagenic urticarias, vibratory angioedema, and exercise-induced anaphylaxis.
\end{abstract}

Keywords: chronic idiopathic urticaria, leukotriene receptor antagonists, montelukast, zafirlukast, antihistamine

Urticaria is a common disorder of the skin, affecting between one in four and one in six people, sometimes throughout their lives. Urticarial episodes of up to 6 weeks' duration are classified as acute, whereas those lasting longer are considered chronic. The clinical characteristic of chronic urticaria (CU) are repeated occurrences of short-lived cutaneous wheals accompanied by redness and itching exceeding 6 weeks. The individual wheals last less than 24 hours, with the exceptions of delayed pressure urticaria and urticarial vasculitis, which persist for 24 to 72 hours. Wheals are lesions ranging from a few millimeters to several centimeters in diameter. The itch of urticaria is the hallmark symptom, and it is usually worse in the evening or nighttime. CU typically follows this diurnal pattern. Angioedema (AE) accompanies $40 \%$ to $50 \%$ of the cases of chronic urticaria and $10 \%$ of the patients experience only AE without hives. ${ }^{1-3}$ In these patients the treatments have focused on symptom control.

\section{Pathogenesis of urticaria}

The weal or hive is the "final pathway" involving dermal mast-cells. This pathway is activated by various trigger factors through immunological or nonimmunological mechanisms and the result is the release of preformed (eg, histamine) and newly synthesized mediators (eg, arachidonic acid metabolites), with potent effects on the micro-vasculature. ${ }^{2}$ 
The most popular theory to explain the development of $\mathrm{CU}$ is referred to as the autoimmune hypothesis. This notion had its origins in 1924, when Lewis and Grant improved the technique of experimentally creating histamine wheals initially described by Eppinger in $1913 .{ }^{4}$

The suggestion that chronic idiopathic urticaria (CIU) may have an autoimmune basis came from the recognition that thyroid auto-antibodies and thyroid dysfunction were observed more commonly in patients with CIU. ${ }^{4}$

The suggestion that a serologic factor is responsible for the pathogenesis of CIU has been a dominant theme in the literature for more than 20 years. In 1986, a serologic mediator called HRF was identified in patients with $\mathrm{CU}$ using an in vivo skin test called the autologous serum skin test (ASST). ${ }^{5}$

We demonstrated that both aspirin (ASA) and food additives determine a significant increase in urinary leukotriene $4\left(\mathrm{LTE}_{4}\right)$ levels, after oral specific challenge in patients with $\mathrm{CU}$ and hypersensitivity to ASA or food additives. The urinary $\mathrm{LTE}_{4}$ levels were compared between patients with $\mathrm{CU}$ and hypersensitivity to ASA or food additives, patients with CU but tolerating both ASA and food additives, and healthy subjects. No difference was found at baseline between the three groups. After a specific challenge with ASA and food additives, the urinary excretion levels of $\mathrm{LTE}_{4}$ were significantly higher in patients affected by $\mathrm{CU}$ and hypersensitivity to ASA or food additives than in patients with CU but without hypersensitivity to ASA or food additives and in healthy subjects. ${ }^{6,7}$

\section{Therapy of urticaria}

The management of CU remains a challenge for both clinicians and patients. Primary recommendations for the management of CU include general measures such as avoidance of any aggravating stimuli, topical antipruritic emollients, reassurance and education, and specific pharmacotherapy, of which the newer selective $\mathrm{H1}$-antihistamines are the preferred intervention. ${ }^{1}$ However, the prior generation "sedating" antihistamines remain useful, efficacious first-line agents for many patients.

Some of these nonselective antihistamines have other useful receptor properties that may extend additional efficacy in certain cases. Such agents include doxepin, cyproheptadine, and ketotifen. ${ }^{8-10}$ The H2-antihistamines are also used in clinical practice, most often as add-on therapy, but these agents generally offer modest incremental efficacy. ${ }^{11}$ In addition to combining multiple antihistamines in such a way, higher doses of antihistamines are widely recommended or prescribed ${ }^{12}$ however, the evidence supporting this practice is minimal. ${ }^{13}$

Oral corticosteroids almost always control urticaria and are undoubtedly the most versatile and useful second-line therapy. However, the incidence of side-effects is substantial if the dose, the duration of use, or both, are too great. ${ }^{14}$ Other second-line therapies include sulphasalazine ${ }^{15}$ and thyroxine. ${ }^{16}$ While third-line, immunosuppressive therapies for severe CU are now accepted practice, there is still the problem of knowing which patients have autoimmune urticaria and are therefore most likely to respond, even if there is some evidence for the therapeutic effect of immunosuppression therapy in patients without autoimmune urticaria. ${ }^{17}$ Newer biologic and nonbiologic immunomodulatory agents, approved for other indications and in clinical development, provide potential options for this often severe CU. ${ }^{18}$

\section{Urticaria treatment with antileukotrienes}

The efficacy and, primarily, safety of the leukotriene modifiers have placed these agents at the top of the list of alternative agents, and future practice may place them alongside antihistamines as first-line therapy. ${ }^{19}$

We searched MEDLINE database and carried out a manual search on journals specializing in allergy and dermatology for the use of antileukotriene drugs in urticaria. Even though treatment with antileukotrienes in urticaria has not been recommended by manufacturers of the drugs, we found numerous anecdotal and open-series reports and some placebo-controlled studies on the treatment of urticaria with cysteinyl-leukotriene antagonists. The studies were evaluated using the parameters of Shekelle (Tables 1,2$).{ }^{20}$

\section{Rationale of the treatment with antileukotrienes}

Injected leukotriene D4 is more potent than histamine in causing a wheal and flare. ${ }^{21}$ Serum from patients with CIU with positive ASST or negative ASST, since patients cannot have both idiopathic and autoimmune disease, is capable of releasing leukotrienes, in addition to other mediators. ${ }^{22}$ Leukotriene-mediated urtication is not blocked by other agents. $^{23}$

\section{Anecdotal series and open studies}

Anecdotal studies suggested therapeutic effects for antileukotrienes in the treatment of urticaria exacerbations induced by $\mathrm{ASA}^{24}$ and other nonsteroidal anti-inflammatory drugs (NSAIDs) in patients with $\mathrm{CIU},{ }^{25}$ chronic autoimmune 
Table I Categories of evidence

\begin{tabular}{ll}
\hline Categories of evidence & \\
\hline la & $\begin{array}{l}\text { Meta-analysis of randomized controlled } \\
\text { trials (RTC) }\end{array}$ \\
Ib & $\begin{array}{l}\text { At least one RTC } \\
\text { Ila }\end{array}$ \\
& $\begin{array}{l}\text { At least one controlled study without } \\
\text { randomization }\end{array}$ \\
IIb & At least one other type of study \\
III & Non-experimental descriptive studies \\
IV & Expert committee reports or opinions \\
& or clinical experience of respected \\
& authorities \\
\hline
\end{tabular}

urticaria, ${ }^{26}$ acquired cold urticaria, ${ }^{27,28}$ delayed-pressure urticaria (DPU), ${ }^{29}$ and intractable CIU. ${ }^{30}$ A single negative study reported a pranlukast-evoked urticaria in patients affected by ASA-induced urticaria. ${ }^{31}$ However, this molecule is not marketed in Europe and in US (Table 3).

Other open studies, with more patients, suggested a beneficial effect for antileukotrienes in the treatment of DPU, ${ }^{32}$ steroid-dependent urticaria ${ }^{33,34}$ chronic idiopathic urticaria, ${ }^{35,36}$ and dermographism. ${ }^{35}$ Patients with allergic urticaria showed less benefit. ${ }^{35}$ Nettis et al treated patients affected by chronic idiopathic urticaria with montelukast or fexofenadine. They demonstrated that montelukast had a better therapeutic effects compared with fexofenadine. The majority of the patients presented a positive ASST and, after therapy with montelukast, were unreactive to autologous serum. ${ }^{37}$

A case report suggested a beneficial effect for antileukotrienes in the treatment of urticaria exacerbation induced by a COX-2 selective inhibitors. ${ }^{38}$ Another study demonstrated in 22/25 patients the effect of antileukotrienes in the treatment of urticaria exacerbation induced by ASA or NSAIDs. ${ }^{39}$ Finally, a comparison between montelukast and cetirizine demonstrated that cetirizine is better than montelukast in monotherapy. ${ }^{40}$

Table 2 Strength of evidence

\begin{tabular}{|c|c|}
\hline Strength of evidence & \\
\hline$A$ & Category I evidence \\
\hline B & $\begin{array}{l}\text { Category II evidence or } \\
\text { extrapolated recommendation } \\
\text { from category I evidence }\end{array}$ \\
\hline C & $\begin{array}{l}\text { Category III evidence or } \\
\text { extrapolated recommendation } \\
\text { from category I or II evidence }\end{array}$ \\
\hline $\mathrm{D}$ & $\begin{array}{l}\text { Category IV evidence or } \\
\text { extrapolated recommendation } \\
\text { from category I or II or III evidence }\end{array}$ \\
\hline
\end{tabular}

\section{Controlled studies}

A double-blind, placebo-controlled study demonstrated a better therapeutic effect of montelukast vs cetirizine and placebo in patients with ASA and/or food additive-induced urticaria. $^{41}$

Perez et al demonstrated that in individuals with histories of recurrent episodes of urticaria andor angioedema after the administration of different NSAIDs, pretreatment with montelukast before a single-blind oral challenge with NSAIDs, completely or partially prevented the reaction in most of those patients. ${ }^{42}$ In a double-blind, placebo-controlled trial comparing cetirizine plus zafirlukast vs cetirizine plus placebo in patients affected by $\mathrm{CU}$ refractory to H1-antagonist monotherapy, Bagenstose et al demonstrated that only patients with autoreactive (positive ASST) CU might benefit from the addition of the leukotriene receptor antagonist zafirlukast to their treatment regimen. ${ }^{43}$

A randomized, single-blind, placebo-controlled, crossover study with montelukast vs placebo, using a nonsedating H1-antihistamine when needed, demonstrated that montelukast might be an effective and safe therapeutic agent in the treatment of patients with refractory chronic idiopathic urticaria, including patients with intolerance to NSAIDs and positivity to ASST. ${ }^{44}$

Reimers et al in a double-blind, placebo-controlled, crossover study, treated with zafirlukast a heterogeneous population of patients with CU. In comparison with placebo, treatment with zafirlukast resulted in no significant positive effect for any of the efficacy measures, but it may be relevant that a high proportion of patients had dermographism. ${ }^{45}$

Nettis et al reported on another randomized, doubleblind, placebo-controlled study conducted on patients with a diagnosis of mild $\mathrm{CU}$, randomized to receive once daily: (a) oral desloratadine plus placebo; (b) desloratadine plus montelukast; or (c) oral placebo alone. In this study, the combination of desloratadine plus montelukast was effective in the treatment of CU. ${ }^{46}$ Di Lorenzo et al treated 160 patients affected by chronic idiopathic urticaria with montelukast alone or in combination with a nonsedating antihistamine (desloratadine), or only with nonsedating antihistamine, or with matched placebo. In this study, we evaluated only patients affected by moderate chronic idiopathic urticaria.

This is an important difference compared with some of the previous reports, in which patients were selected without precise characteristics. ${ }^{33,34,46}$ In patients with moderate chronic idiopathic urticaria, the role of leukotrienes is probably rather insignificant. ${ }^{6,43}$ In this study, montelukast alone 


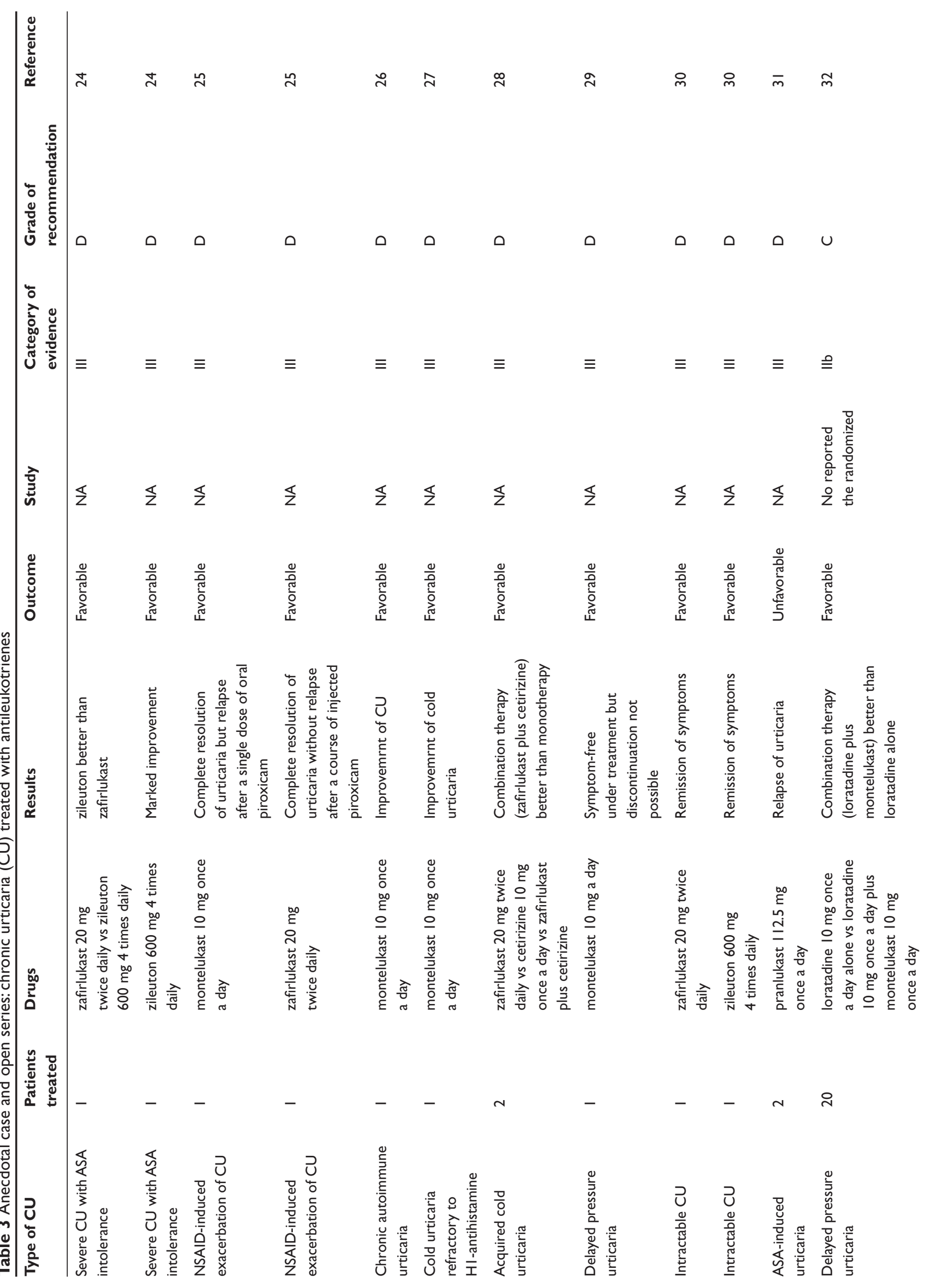




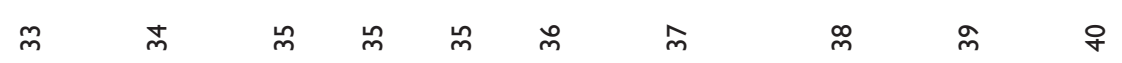

$\triangleq \quad \equiv \quad \equiv \quad \equiv \quad \equiv \quad \equiv$

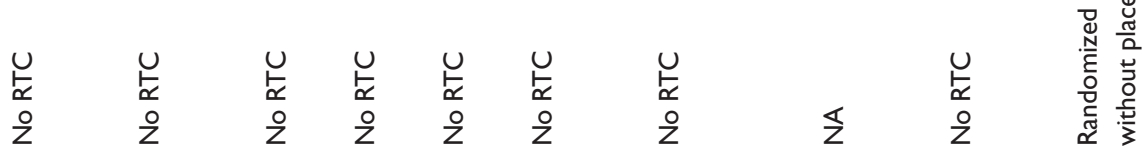

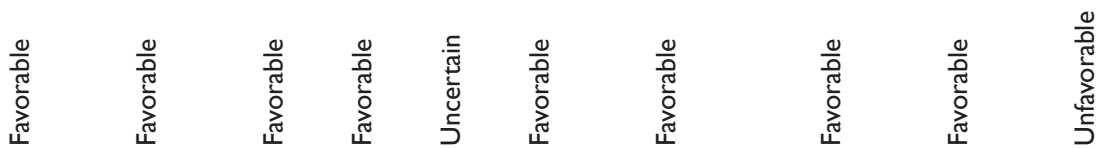

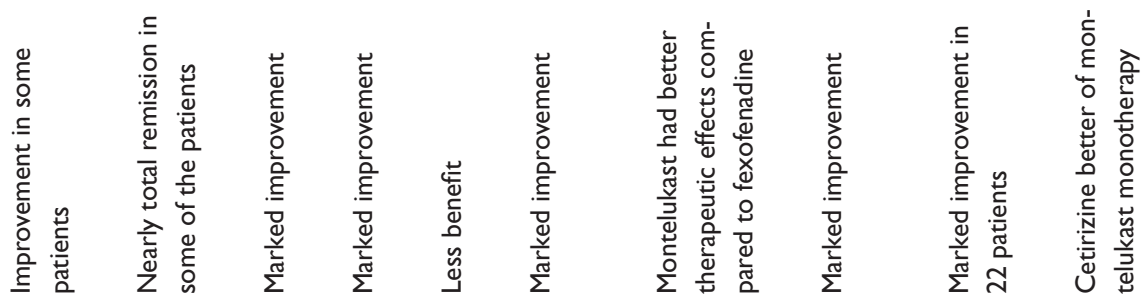

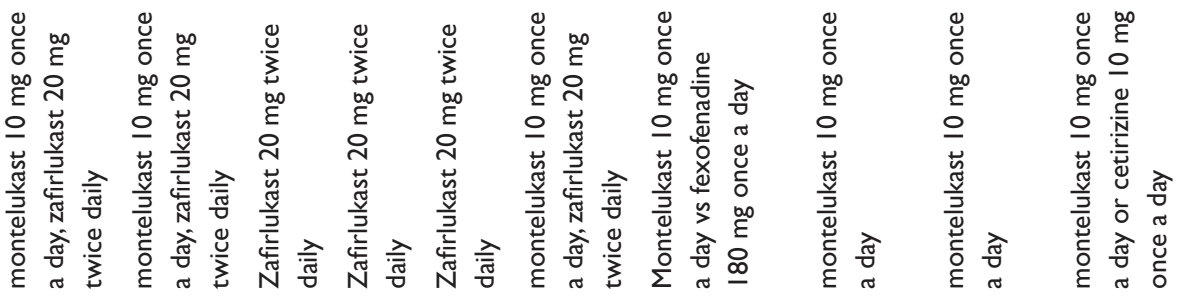

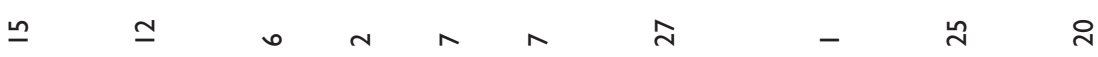

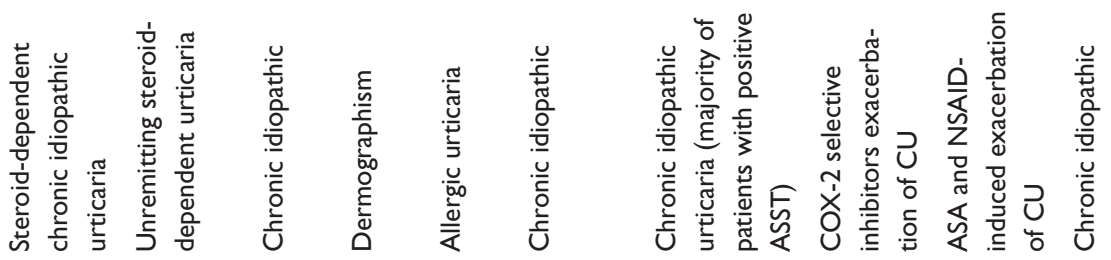




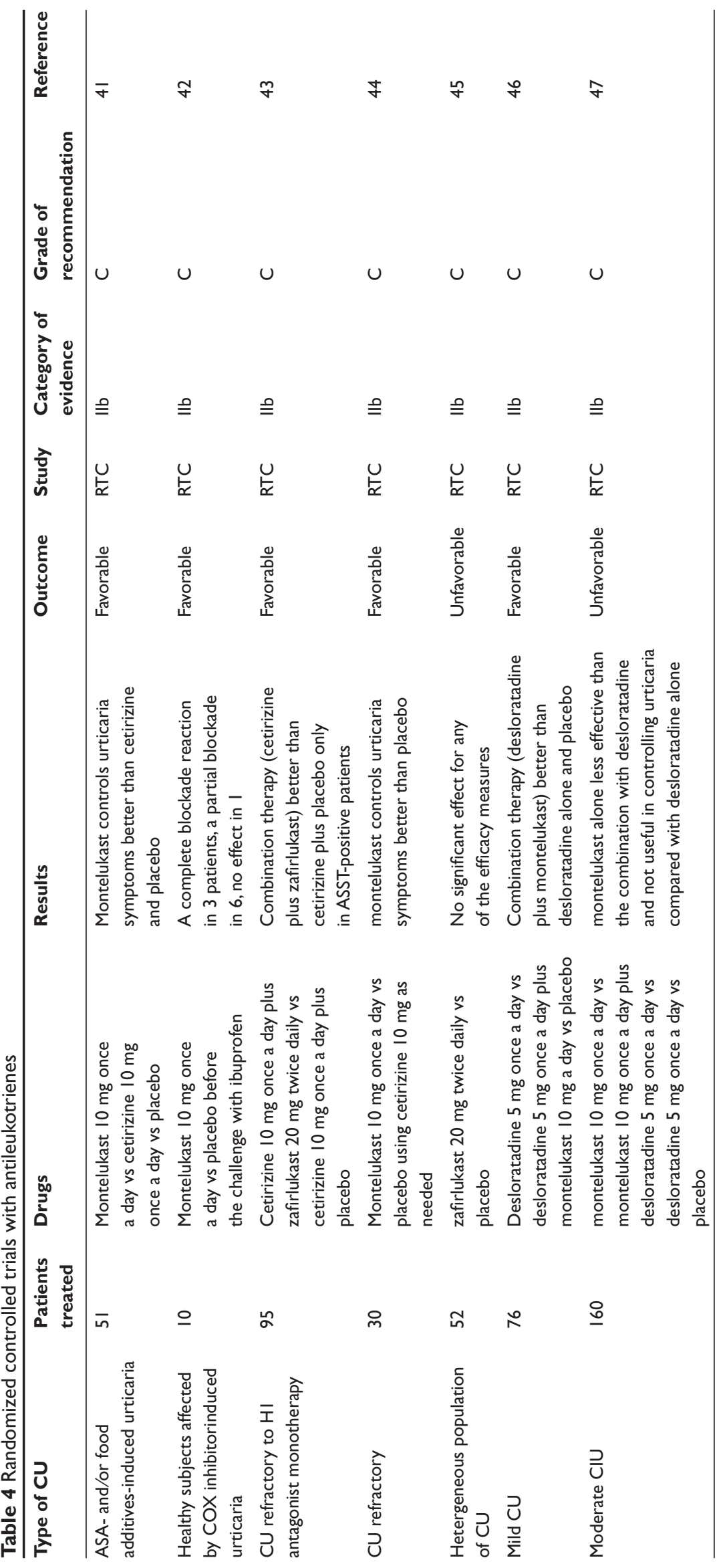


was less effective than the combination with nonsedating antihistamine and appeared not to be useful in controlling the symptoms of urticaria compared with nonsedating antihistamine alone. Therefore, the expected synergistic interaction between antileukotrienes and antihistamines was not confirmed in mild chronic idiopathic urticaria. ${ }^{47}$ This result is in accordance with another noncontrolled study ${ }^{40}$ (Table 4).

\section{Conclusions}

Leukotriene receptor antagonists are currently the beststudied group of drugs after the antihistamines, in the therapy of CU. However, the leukotriene receptor antagonists aren't alternative agents to antihistamines. The excellent safety, absence of required monitoring in the case of montelukast and zafirlukast, and wide availability make leukotriene receptor antagonists the preferred supplementary agents to try with antihistamines. Although one study suggested persistent drug-free remission, ${ }^{44}$ most experience argues against such a disease-modifying effect. Leukotriene receptor antagonists appear to be useful as both monotherapy and add-on therapy but are not likely to displace antihistamines from their role as first-line therapy.

In our review, leukotriene receptor antagonists may provide improvement in patients with food additive hypersensitivity or ASA and other NSAID-exacerbated CIU $^{24,25,31,38,39,41,42}$ and in patients with positive ASST results. ${ }^{26,37,44}$ In other words, in the type of chronic urticaria without any associated cause, very idiopathic urticaria, the use of leukotriene receptor antagonists demonstrates lack of advantage if administered both in monotherapy and combined with antihistamines.

\section{Disclosures}

The authors have no conflicts of interest to disclose.

\section{References}

1. Greaves M. Chronic urticaria. J Allergy Clin Immunol. 2000;105: 664-672

2. Kaplan AP. Clinical practice. Chronic urticaria and angioedema. NEngl J Med. 2002;346:175-179.

3. Grattan CE. The urticaria spectrum: recognition of clinical patterns can help management. Clin Exp Dermatol. 2004;29:217-221.

4. Brodell LA, Beck LA, Saini SS. Pathophysiology of chronic urticaria. Ann Allergy Asthma Immunol. 2008;100:291-297.

5. Grattan CE, Boon AP, Eady RA, Winkelmann RK. The pathology of the autologous serum skin test response in chronic urticaria resembles IgE-mediated late-phase reactions. Int Arch Allergy Appl Immunol. 1990;93:198-204.

6. Di Lorenzo G, Pacor ML, Vignola AM, et al. Urinary metabolites of histamine and leukotrienes before and after placebo-controlled challenge with ASA and food additives in chronic urticaria patients. Allergy. 2002;57:1180-1186.
7. Di Lorenzo G, Pacor ML, Mansueto P, et al. Food-additive-induced urticaria: a survey of 838 patients with recurrent chronic idiopathic urticaria. Int Arch Allergy Immunol. 2005;138:235-242.

8. Goldsobel AB, Rohr AS, Siegel SC, et al. Efficacy of doxepin in the treatment of chronic idiopathic urticaria. J Allergy Clin Immunol. 1986;78:867-873.

9. Wanderer AA, St Pierre JP, Ellis EF. Primary acquired cold urticaria: double-blind comparative study of treatment with cyproheptadine, chlorpheniramine, and placebo. Arch Dermatol. 1977;113:1375-1377.

10. Kamide R, Niimura M, Ueda H, et al. Clinical evaluation of ketotifen for chronic urticaria: multicenter double-blind comparative study with clemastine. Ann Allergy. 1989;62:322-325.

11. Monroe EW, Cohen SH, Kalbfleisch J, Schulz CI. Combined H1 and $\mathrm{H} 2$ antihistamine therapy in chronic urticaria. Arch Dermatol. 1981;117:404-407.

12. Zuberbier T, Bindslev-Jensen C, Canonica W, et al. EAACI/GA2LEN/ EDF guideline: management of urticaria. Allergy. 2006;61:321-331.

13. Zuberbier T, Munzberger C, Haustein U, et al. Double-blind crossover study of high-dose cetirizine in cholinergic urticaria. Dermatology. 1996;193:324-327.

14. Kaplan AP. Chronic urticaria: pathogenesis and treatment. J Allergy Clin Immunol. 2004;114:465-474.

15. Engler RJ, Squire E, Benson P. Chronic sulfasalazine therapy in the treatment of delayed pressure urticaria and angioedema. Ann Allergy Asthma Immunol. 1995;74:155-159.

16. Gaig P, Garcia-Ortega P, Enrique E, Richart C. Successful treatment of chronic idiopathic urticaria associated with thyroid autoimmunity. J Invest Allergy Clin Immunol. 2000;10:342-5.

17. Grattan CE, O'Donnell BF, Francis DM, et al. Randomized double-blind study of cyclosporin in chronic 'idiopathic' urticaria. Br J Dermatol. 2000; $143: 365-372$.

18. Bingham III CO. Immunomodulatory approaches to the management of chronic urticaria: an immune-mediated inflammatory disease. Curr Allergy Asthma Rep. 2008;8:278-287.

19. Di Lorenzo G, Pacor ML, Mansueto P, et al. Is there a role for antileukotrienes in urticaria? Clin Exp Dermatol. 2006;31:327-334.

20. Shekelle PG, Woolf SH, Eccles M, Grimshaw J. Clinical guidelines: developing guidelines. BMJ. 1999;318:593-596.

21. Maxwell DL, Atkinson BA, Spur BW, Lessof MH, Lee TH. Skin responses to intradermal histamine and leukotrienes $\mathrm{C} 4, \mathrm{D} 4$, and E4 in patients with chronic idiopathic urticaria and in normal subjects J Allergy Clin Immunol. 1990;86:759-765.

22. Wedi B, Novacovich V, Koerner M, Kapp A. Chronic urticaria serum induces histamine release, leukotriene production, and basophil CD63 surface expression: inhibitory effects of anti-inflammatory drugs. J Allergy Clin Immunol. 2000;105:552-560.

23. Bisgaard H. Vascular effects of leukotriene D4 in human skin. J Invest Dermatol. 1987;88:109-114.

24. Ellis MH. Successful treatment of chronic urticaria with leukotriene antagonists. J Allergy Clin Immunol. 1998;102:876-877.

25. Asero R. Leukotriene receptor antagonists may prevent NSAID-induced exacerbations in patients with chronic urticaria. Ann Allergy Asthma Immunol. 2000;85:156-157.

26. Tedeschi A, Suli C, Lorini M, Airaghi L. Successful treatment of chronic urticaria. Allergy. 2000;55:1097-1098.

27. Hani N, Hartmann K, Casper C, et al. Improvement of cold urticaria by treatment with the leukotriene receptor antagonist montelukast. Acta Derm Venereol. 2000;80:229.

28. Bonadonna P, Lombardi C, Senna G, Canonica GW, Passalacqua G. Treatment of acquired cold urticaria with cetirizine and zafirlukast in combination. J Am Acad Dermatol. 2003;49:714-716.

29. Berkun Y, Shalit M. Successful treatment of delayed pressure urticaria with montelukast. Allergy. 2000;55: 203-204

30. Spector S, Tan RA. Antileukotrienes in chronic urticaria. J Allergy Clin Immunol. 1998;101:572.

31. Ohnishi-Inoue Y, Mitsuya K, Horio T. Aspirin-sensitive urticaria: provocation with a leukotriene receptor antagonist. $\mathrm{Br} J$ Dermatol. 1998;138:483-485. 
32. Nettis E, Pannofino A, Cavallo E, Ferrannini A, Tursi A. Efficacy of montelukast, in combination with loratadine, in the treatment of delayed pressure urticaria. J Allergy Clin Immunol. 2003;112: 212-213.

33. Norris JG, Sullivan TJ. Leukotrienes and cytokines in steroid dependent chronic urticaria. J Allergy Clin Immunol. 1998;101:S128.

34. Asero R, Tedeschi A, Lorini M. Leukotriene receptor antagonists in chronic urticaria. Allergy. 2001;56:456-457.

35. Chu TJ, Warren MS. Zafirlukast (ACCOLATE_) in the treatment of chronic idiopathic urticaria - a case series. J Allergy Clin Immunol. 1998;101:S155.

36. Bensch GW, Borish L. Leukotriene receptor antagonists in the treatment of chronic idiopathic urticaria. J Allergy Clin Immunol. 1999;103:S154.

37. Nettis E, Dambra P, D’Oronzio L, Loria MP, Ferrannini A, Tursi A. Comparison of montelukast and fexofenadine for chronic idiopathic urticaria. Arch Dermatol. 2001;137:99-100.

38. Serrano C, Valero A, Picado C. Usefulness of montelukast to prevent adverse reactions to COX-2 selective inhibitors: a case report. J Investig Allergol Clin Immunol. 2005;15:156-157.

39. Goel A, Prasad D. Oral monteleukast in urticaria induced by nonsteroidal anti-inflammatory drugs. J Eur Acad Dermatol Venereol. 2007;21:1275-1276.

40. Godse KV. Oral montelukast monotherapy is ineffective in chronic idiopathic urticaria: a comparison with oral cetirizine. Indian J Dermatol Venereol Leprol. 2006;72:312-314.
41. Pacor ML, Di Lorenzo G, Corrocher R. Efficacy of leukotriene receptor antagonist in chronic urticaria. A double-blind, placebo-controlled comparison of treatment with montelukast and cetirizine in patients with chronic urticaria with intolerance to food additive and/or acetylsalicylic acid. Clin Exp Allergy. 2001;31:1607-1614.

42. Perez C, Sanchez-Borges M, Capriles E. Pretreatment with montelukast blocks NSAID-induced urticaria and angioedema. J Allergy Clin Immunol. 2001;108:1060-1061.

43. Bagenstose SE, Levin L, Bernstein JA. The addition of zafirlukast to cetirizine improves the treatment of chronic urticaria in patients with positive autologous serum skin test results. J Allergy Clin Immunol. 2004;113:134-140.

44. Erbagci Z. The leukotriene receptor antagonist montelukast in the treatment of chronic idiopathic urticaria: a single-blind, placebo-controlled, crossover clinical study. J Allergy Clin Immunol. 2002;110:484-488.

45. Reimers A, Pichler C, Helbling A, Pichler WJ, Yawalkar N. Zafirlukast has no beneficial effects in the treatment of chronic urticaria. Clin Exp Allergy. 2002;32:1763-1768.

46. Nettis E, Colanardi MC, Paradiso MT, Ferrannini A. Desloratadine in combination with montelukast in the treatment of chronic urticaria: a randomized, double-blind, placebo-controlled study. Clin Exp Allergy. 2004;34:1401-1407.

47. Di Lorenzo G, Pacor ML, Mansueto P, et al. Randomized placebocontrolled trial comparing desloratadine and montelukast in monotherapy and desloratadine plus montelukast in combined therapy for chronic idiopathic urticaria. J Allergy Clin Immunol. 2004;114:619-625. 